\title{
Congenital Diaphragmatic Hernia: Experience and Results of Thoracoscopic Repair from a Tertiary Care Hospital
}

\author{
Vaibhav Pandey ${ }^{1}$ Saroj C. Gopal ${ }^{1}$ \\ ${ }^{1}$ Department of Pediatric Surgery, Institute of Medical Sciences, \\ Banaras Hindu University, Varanasi, Uttar Pradesh, India
}

\begin{abstract}
Address for correspondence Vaibhav Pandey, MS, MCh, Department of Pediatric Surgery, Institute of Medical Sciences, Banaras Hindu University, Varanasi 221005, Uttar Pradesh, India (e-mail: vaibhavpedbhu@gmail.com).
\end{abstract}

Abstract
Keywords
- congenital
diaphragmatic hernia
- thoracoscopy
- pediatric age
- minimal access
surgery

Introduction Congenital diaphragmatic hernia $(\mathrm{CDH})$ is one of the most common congenital anomalies encountered by pediatric surgeons. With the advances in the pediatric minimal access surgery, its role in the repair of $\mathrm{CDH}$ has also increased. We have been using thoracoscopy for the repair for CDH since 2015. We herein report our experience of $\mathrm{CDH}$ repair in newborns.

Materials and Methods A retrospective review was conducted from July 2015 to December 2019 in the Department of Pediatric surgery after ethical approval from the institutional review board and included all the children with $\mathrm{CDH}$ who underwent thoracoscopic repair. The case records were used to assess the demographic details, type of defect, and early and late postoperative complications of thoracoscopy in CDH. Results Thoracoscopic repair was attempted in 29 patients of $\mathrm{CDH}$. Eight (27.5\%) patients converted to open procedure and were excluded from the study. Primary closure of the diaphragmatic defect was performed in $90.4 \%$ (19) patients. Also, 9.5\% (2) children required mesh repair. There was no intraoperative death. Postoperative ventilation was required in $57.1 \%$ (12) children. The mean time on the ventilator was $3.03 \pm 0.9$ days. The mean age of children requiring postoperative ventilation was less compared with children who were extubated in the postoperative period $(p=0.032)$. The median follow-up in our study was 12 months and $28.5 \%$ of patients developed recurrence of the diaphragmatic hernia. All the children underwent laparotomy and repair of the diaphragmatic defect.

Conclusion Thoracoscopic repair is a safe and effective option for the repair of CDH in children performed by surgeons with significant procedure experience.

\section{Introduction}

Congenital diaphragmatic hernia $(\mathrm{CDH})$ is one of the most common congenital anomalies encountered by pediatric surgeons. The advances in neonatal management and fetal intervention have decreased the overall mortality, but still, the mortality is high in cases with poor prognosis. ${ }^{1,2}$ With improving overall survival, the long-term morbidity and mortality have also come into the picture. ${ }^{3}$ Early and late

DOI https://doi.org/ $10.1055 / \mathrm{s}-0040-1714200$ ISSN 0379-038X. complications with open surgery like adhesive obstruction and multiple interventions in cases with complication or recurrence adds to long-term morbidity and mortality. The minimal access surgery has shown a better outcome with respect to these complications. With the advent of pediatric minimal access surgery, its use in the $\mathrm{CDH}$ repair has also increased. Early reports have shown a decreased morbidity and improved long-term outcome with the thoracoscopic repair of $\mathrm{CDH},{ }^{4,5}$ Different authors have reported their 
experiences with the variable outcome and a limited number of patients, especially the newborns. ${ }^{6,7}$ We have been using thoracoscopic repair for CDH repair since 2015. We herein report our experience of $\mathrm{CDH}$ repair in children.

\section{Materials and Methods}

A retrospective review was conducted from July 2015 to December 2019 at the department of pediatric surgery after ethical approval from the institutional review board and included all children with CDH who were repaired thoracoscopically. The case records were used to assess the demographic details, type of defect, and early and late postoperative complications. The diagnosis was made by the $\mathrm{X}$-ray chest in all the patients.

\section{Operative Technique}

We used the standard three-port technique for thoracoscopic repair of $\mathrm{CDH}$. After endotracheal intubation, the patients were placed in lateral decubitus position and stabilized. Pneumothorax was created with the Veress needle, inserting it just below the scapular tip in the midaxillary line followed by carbon dioxide insufflation up to a pressure of 3 to $5 \mathrm{~mm} \mathrm{Hg}$. The Veress needle was replaced with $5-\mathrm{mm}$ port for 30-degree telescopes. The herniating contents were visualized and gradually pushed into the abdomen with the telescope itself, under vision to create space. The pneumothorax helps in the reduction of contents into the abdomen. Following this partial reduction, the pressure is gradually increased to 5 to $6 \mathrm{~mm} \mathrm{Hg}$, and then two more 3-mm trocars are placed under vision in the anterior and posterior axillary line, just cephalad to camera port, utilizing maximum space to achieve the triangulation. However, the triangulation is not possible because of the limited space. After reducing the contents, the hernia defect was repaired using nonabsorbable interrupted sutures (polyester $2 / 0$ or polypropylene 2-0 or polyamide 2-0) encompassing two borders of the diaphragmatic muscle defect with intracorporeal knotting (-Figs. 1-3). The rim of the defect was sewn to the thoracic wall when adequate rim was not present. A chest drain was inserted in the lowest port posteriorly. It was withdrawn when the thoracic X-ray result was normal.

\section{Results}

During the study period, the thoracoscopic repair of $\mathrm{CDH}$ was attempted in 29 cases. The conversion to open surgery was required in eight $(27.5 \%)$ cases. All these cases were managed by laparotomy via subcostal incision and repair of the diagrammatic defect was performed. The conversion in six (75.0\%) cases was done because of hemodynamic instability. In two cases, the spleen could not be reduced due to congestion enlargement. So, there were 21 patients, including 14 boys and 7 girls who underwent thoracoscopic repair of $\mathrm{CDH}$. Nine $(42.0 \%)$ cases were operated in the neonatal period. The median age of the other 12 cases was

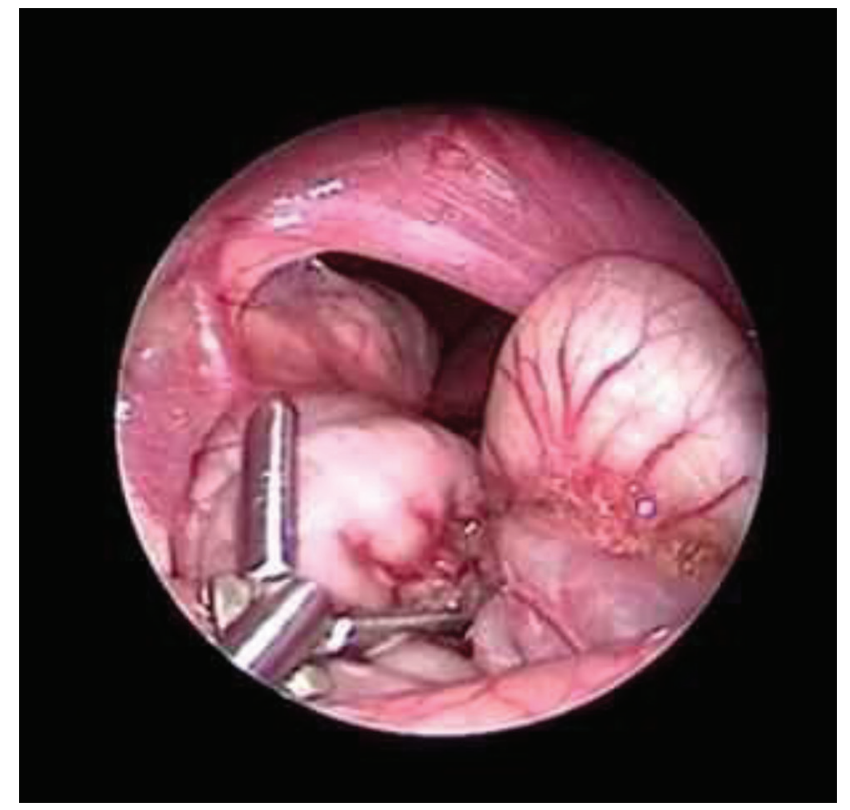

Fig. 1 Posterolateral diaphragmatic defect with small bowel in hemithorax.

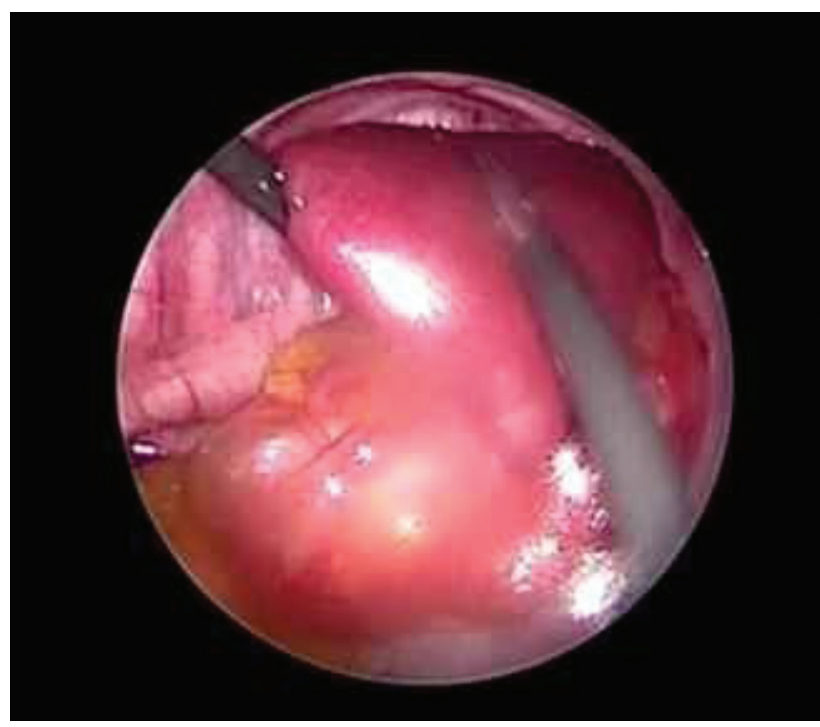

Fig. 2 Spleen in hemithorax as content of hernia.

7.5 months (interquartile range: $4.0-10.6$ months) months. Neonates presented with a history of respiratory distress at birth, while the older children presented with a history of repeated chest infection, multiple hospital admissions, and failure to thrive. The hernia was located on the left side in 19 patients and on the right side in 2 patients (-Table $\mathbf{1}$ ). We were able to close the defect primarily in 19 patients. In two patients, thoracoscopic mesh repair was performed. Plication of sac followed by repair was done in four cases with sac. The mean operative time was $92.3 \pm 20.4$ minutes and there was no significant blood loss in any of the cases. A chest drain was inserted in all patients. There was no intraoperative death. Postoperative ventilation was required in $12(57.1 \%)$ children. The mean time on the ventilator was 


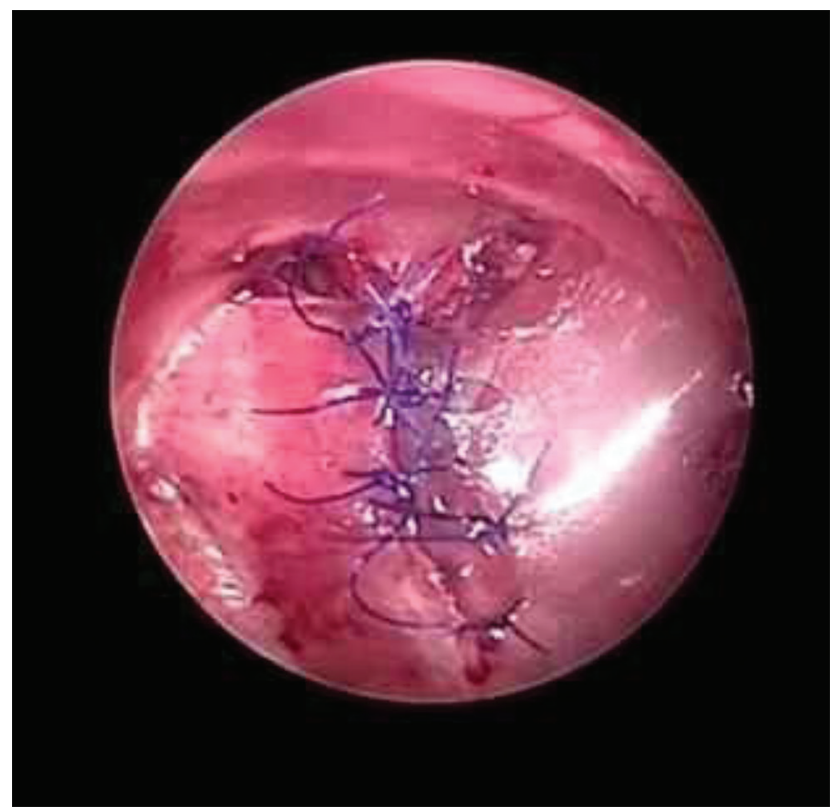

Fig. 3 Closed defect with interrupted Prolene 2-0 interrupted sutures.

Table 1 Demographic details of patients

\begin{tabular}{|l|l|l|}
\hline \multirow{2}{*}{ Age } & \multicolumn{2}{|l|}{ Characteristics $(\boldsymbol{n}=\mathbf{2 1})$} \\
\hline \multirow{2}{*}{ Gender } & Neonatal & $9(42.8 \%)$ \\
\cline { 2 - 3 } & Postneonatal & $12(57.1 \%)$ \\
\hline \multirow{2}{*}{ Side } & Male & $14(66.6 \%)$ \\
\cline { 2 - 3 } & Female & $7(33.3 \%)$ \\
\hline \multirow{2}{*}{ Repair } & Right & $2(9.5 \%)$ \\
\cline { 2 - 3 } & Left & $19(90.4 \%)$ \\
\hline Mean duration of surgery & Primary & $19(90.4 \%)$ \\
\cline { 2 - 3 } & Mesh repair & $2(9.5 \%)$ \\
\hline
\end{tabular}

$3.03 \pm 0.9$ days. The mean age of children requiring postoperative ventilation was ( $24.0 \pm 6.8$ days) less than those who did not require ventilation in postoperative period (52.8 \pm 13.9 days) $(p=0.032)$. Two children with ventilation requirement died due to ventilator associate pneumonia in the postoperative period. The mean postoperative hospitalization was $7.4 \pm 3.2$ days. The median follow-up of children was 12 months (range: 6-36 months). Six patients developed recurrence within one year of repair. All these six children underwent laparotomy for the repair of the diaphragmatic defect.

\section{Discussion}

The management of $\mathrm{CDH}$ has undergone a sea change, from an earlier concept of immediate repair to the modern understanding of stabilization and delayed repair. ${ }^{1}$ The understanding of the pathogenesis and prognostic factors have led to a modification in the resuscitation and surgical techniques. Following the first successful thoracoscopic repair of $\mathrm{CDH}$ by Becmeur et $\mathrm{al}^{8}{ }^{8}$ different centers followed-up with their experience. The results were mixed. Multiple small studies showed thoracoscopic repair to be safe and effective for CDH with the better cosmetic outcome, decreased rates of adhesive obstruction in follow-up, and decreased pain in postoperative period. ${ }^{9,10}$ On the contrary to these findings, other studies did not reveal any advantage of the thoracoscopic approach. Further, this was associate with an increased rate of recurrence ${ }^{11,12}$ with persisting concern about hypercapnia and acidosis. ${ }^{13}$ Most of the evidence available is in the form of small retrospective. But there is a growing concern about the thoracoscopic repair as the long-term data and larger studies are coming. One of the largest studies published by CDH study group has shown significantly higher recurrence rate with the thoracoscopic repair of $\mathrm{CDH}^{14}$ The study examined data from 4,526 infants who had a CDH repair, of which 151 had minimally invasive repairs. The minimally invasive repairs had a 7.9 versus $2.7 \%$ recurrence rate for open, a statistically significant difference. In our series, we have an overall recurrence rate of $28.5 \%$, which is very high compared with other series. But only one (9\%) child had recurrence out of the last 11 cases. Also, $50 \%$ of the first 10 cases had a recurrence. As we have been through our learning curve, we have managed to decrease the recurrence rates by adhering to a few principles. One of the important factors for a longer learning curve in pediatric patients is limited space. For better manipulation of instruments and proper visualization during an endoscopic procedure, trocars should be placed in a triangular fashion. In children, especially in neonates, it is very difficult to achieve because of the small size of the thoracic cavity and the presence of ribs. This does not allow ideal port placement in most of the cases and makes the handling of suture difficult. ${ }^{15}$ We have increased the number of sutures and thus decreased the gap. Further, we have started using mesh (polypropylene) in cases with larger gap and undue tension. Different long-term studies have proven the benefit of thoracoscopic repair in the positive outcomes in terms of bowel obstruction. We also did not observe any case with adhesive obstruction in our series. The results were similar to other studies. ${ }^{14,16}$ There is significant longterm decrease in the number of admissions due to adhesive obstruction, relaparotomies due to bowel obstruction, and overall mortality. ${ }^{6}$ Laparoscopic approach has also been advocated by different groups for the repair of $\mathrm{CDH}^{8,17} \mathrm{But}$ the laparoscopy is associate with difficulty in reduction of the contents. Trauma while pulling the contents into the abdomen. Further, the pneumoperitoneum is against and pushes the contents back into the chest. Thoracoscopy provides all these advantages over the laparoscopy. ${ }^{18,19}$ The suturing is also difficult by laparoscopy approach as bowel comes and obscures the field. We present our series of thoracoscopic procedures for $\mathrm{CDH}$ repair during 4-year-period. Our study showed that thoracoscopic repair is safe and feasible for $\mathrm{CDH}$ in children and newborns. Our experience is similar to other authors who have also experienced the improved efficacy rates of thoracoscopic repair with experience. 


\section{Conclusion}

The outcome of thoracoscopic repair of congenital diaphragmatic hernia depends on the competency of surgeon and their learning curve. It is a safe and effective option with excellent outcome in the hands of a competent surgeons.

\section{Authors' Contributions}

S.C.G. contributed in study conception and design, drafting the manuscript, and critical revision. V.P. contributed in study conception and design analysis and data interpretation, data acquisition, and drafting of the manuscript.

\section{Conflict of Interest}

None declared.

\section{References}

1 Smith NP, Jesudason EC, Featherstone NC, Corbett HJ, Losty PD. Recent advances in congenital diaphragmatic hernia. Arch Dis Child 2005;90(4):426-428

2 Friedmacher F, Pakarinen MP, Rintala RJ. Congenital diaphragmatic hernia: a scientometric analysis of the global research activity and collaborative networks. Pediatr Surg Int 2018;34(9):907-917

3 Leeuwen L, Fitzgerald DA. Congenital diaphragmatic hernia. J Paediatr Child Health 2014;50(9):667-673

4 Tyson AF, Sola R Jr, Arnold MR, Cosper GH, Schulman AM. Thoracoscopic versus open congenital diaphragmatic hernia repair: single tertiary center review. J Laparoendosc Adv Surg Tech A 2017;27(11):1209-1216

5 Jain V, Agarwala S, Bhatnagar V. Recent advances in the management of congenital diaphragmatic hernia. Indian J Pediatr 2010;77(6):673-678

6 Gomes Ferreira C, Reinberg O, Becmeur F, et al. Neonatal minimally invasive surgery for congenital diaphragmatic hernias: a multicenter study using thoracoscopy or laparoscopy. Surg Endosc 2009;23(7):1650-1659

7 Barroso C, Correia-Pinto J. Thoracoscopic repair of congenital diaphragmatic hernia: review of the results. Minerva Pediatr 2018;70(3):281-288
8 Becmeur F, Jamali RR, Moog R, et al. Thoracoscopic treatment for delayed presentation of congenital diaphragmatic hernia in the infant. A report of three cases. Surg Endosc 2001;15(10):1163-1166

9 Lao OB, Crouthamel MR, Goldin AB, Sawin RS, Waldhausen JHT, Kim SS. Thoracoscopic repair of congenital diaphragmatic hernia in infancy. J Laparoendosc Adv Surg Tech A 2010;20(3):271-276

10 Liem NT. Thoracoscopic approach in management of congenital diaphragmatic hernia. Pediatr Surg Int 2013;29(10):1061-1064

11 Okazaki T, Okawada M, Ishii J, et al. Intraoperative ventilation during thoracoscopic repair of neonatal congenital diaphragmatic hernia. Pediatr Surg Int 2017;33(10):1097-1101

12 Huang JS, Lau CT, Wong WYY, Tao Q Wong KK, Tam PKH. Thoracoscopic repair of congenital diaphragmatic hernia: two centres' experience with 60 patients. Pediatr Surg Int 2015;31(2):191-195

13 Schneider A, Becmeur F. Pediatric thoracoscopic repair of congenital diaphragmatic hernias. J Vis Surg 2018;4:43

14 Tsao K, Lally PA, Lally KP; Congenital Diaphragmatic Hernia Study Group. Minimally invasive repair of congenital diaphragmatic hernia. J Pediatr Surg 2011;46(6):1158-1164

15 von Renteln D, Vassiliou MC, Rösch T, Rothstein RI. Triangulation: the holy grail of endoscopic surgery? Surg Endosc 2011;25(5):1355-1357

16 Shah SR, Wishnew J, Barsness K, et al. Minimally invasive congenital diaphragmatic hernia repair: a 7-year review of one institution's experience. Surg Endosc 2009;23(6):1265-1271

17 He Q Zhong W, Wang Z, Yan B, Xie X, Yu J. Simple and safe thoracoscopic repair of neonatal congenital diaphragmatic hernia by a new modified knot-tying technique. Hernia 2019;23(6):1275-1278

18 Fujishiro J, Ishimaru T, Sugiyama M, et al. Minimally invasive surgery for diaphragmatic diseases in neonates and infants. Surg Today 2016;46(7):757-763

19 Vijfhuize S, Deden AC, Costerus SA, Sloots CEJ, Wijnen RMH. Minimal access surgery for repair of congenital diaphragmatic hernia: is it advantageous?-An open review. Eur J Pediatr Surg 2012;22(5):364-373 